\title{
Dual Band Circularly Polarized Printed Antenna with Branched Microstrip Feed
}

\author{
Usama A. Mashayak \\ PG Department \\ MBES's College of Engineering \\ Ambajogai, India, 431517
}

\author{
Veeresh G. Kasabegoudar \\ PG Department \\ MBES's College of Engineering \\ Ambajogai, India, 431517
}

\begin{abstract}
In this paper compact microstrip antenna with dual band circularly polarization has presented. Dual band for circular polarization is obtained using modified ground plane and by adding stubs to the feed line. The overall dimensions of the proposed antenna are $38 \mathrm{~mm} \times 55 \mathrm{~mm} \times 1.6 \mathrm{~mm}$. The antenna design is simulated using HFSS v.13 software which gives frequencies from $2.61-2.93 \mathrm{GHz}$ (first band) and from 4.24$4.41 \mathrm{GHz}$ (second band). Moreover, the proposed antenna provides reasonably good axial ratio bandwidth and return loss bandwidth for both the working bands. Proposed design is fabricated and measured.
\end{abstract}

\section{General Terms}

Microstrip antenna, Dual band circular polarization

\section{Keywords}

Circularly Polarized antenna, Monopole Antenna, Branched feed, CPW, Dual Band Antenna

\section{INTRODUCTION}

Since the enormous use of wireless devices and handheld devices there is requisite need of special type of antennas called as circularly polarized (CP) antennas. CP antenna can also provide a better immunity over multi-path fading channel [1]. Another sophisticated and prominent feature of $\mathrm{CP}$ is that it does not require precise orientation for devices to transmit and receive, making it more popular and flexible in handling for wireless devices users. The circularly polarized (CP) antenna can receive the incident waves of any polarization and its radiating circularly polarized wave can be easily received by antenna of any polarization except for its orthogonal polarization wave [2]. Therefore, the circularly polarized antennas are often utilized in radar, satellite, radio frequency identification (RFID), navigation, and sensor systems [3]. There are many challenges in design of circularly polarized (CP) antennas. Some of them are miniaturization, low manufacturing cost, high axial ratio bandwidth, etc.

In recent years, because of whopping applications demand in wireless communication systems there is need for greater capacities broadband service to support wireless devices. This increased demands leads to massive researches on design of printed circularly polarized antennas and various types of $\mathrm{CP}$ slot antennas have been proposed, such as CPW-fed strip loaded square slot antenna with four metallic strips at the four corners in [4], Creating an L-shaped slot on the ground plane [5], protruding a T-shaped metallic strip from the ground plane towards the slot center [6], a cross patch-loaded square slot antenna [7], widened L-type strip square slot antenna [8], and a pair of inverted-L grounded strips [9]. Broadband CP antenna with branched feed gives good axial ratio bandwidth [10]. However, all these designs have single operational band.

Apparently, in recent cellular world one operational band creates bottleneck for different wireless services to be incorporated in a single device so there is integral need for multiband CP antenna. While designing them it has many challenges like axial ratio bandwidth, return loss bandwidth, etc. which are already narrower in CP antenna. So this will fascinate many researchers to immerse them in this work. Many designs to develop dual-band circularly polarized antennas have been proposed in [11-13]. The antenna with circular patch surrounded by two concentric annular-rings and an unequal lateral cross-slot loaded ground plane is proposed, nevertheless, it only has about $1 \%$ dual $\mathrm{CP}$ bandwidths and around 6\% axial ratio bandwidths [11]. Another research proposes the antenna with the stacked-patch configuration having unequal $\mathrm{U}$-slots to achieve the dual-band $\mathrm{CP}$ successfully; both the impedance bandwidths and $\mathrm{CP}$ bandwidths are relatively narrow with the cost of multilayered design [12]. The antenna in [13] has a complex design but gives reasonably good bandwidth.

Because coplanar waveguide (CPW) fed printed slot antennas have lots of attractive features such as wide impedance, single metallic layer and easy integration with active devices, they are enormously used in design of CP antennas [14-17]. There are several studies that have used CPW-fed structure to implement wide-band $\mathrm{CP}$ antennas for various applications such as WLAN and Ultra-wideband (UWB) [18-20].

Therefore, in this paper, a circularly polarized antenna with branched microstrip feed on the back side and monopole with slotted ground on front side which creates CPW feeding. By employing slot and branched microstrip feed we can excite monopole and slot in parallel to get two orthogonal modes and circular polarization is obtained. The proposed antenna geometry with its parameters is presented in Section 2. The parametric optimization is carried out using Ansoft's HFSS v.13 and the various results obtained from this study are presented in section 3. Experimental validations and fabricated prototype explained in section 4. Finally, the conclusions of this study are presented in Section 5 .

\section{ANTENNA DESIGN AND CONFIGURATION}

Figure 1 depicts the basic geometry of proposed circularly polarized antenna for dual band operation. The antenna is printed on a rectangular FR4 dielectric substrate with a relative permittivity of 4.4 and a thickness of $1.6 \mathrm{~mm}$. The overall dimensions of proposed antenna are $38 \times 55 \times 1.6 \mathrm{~mm}$. 


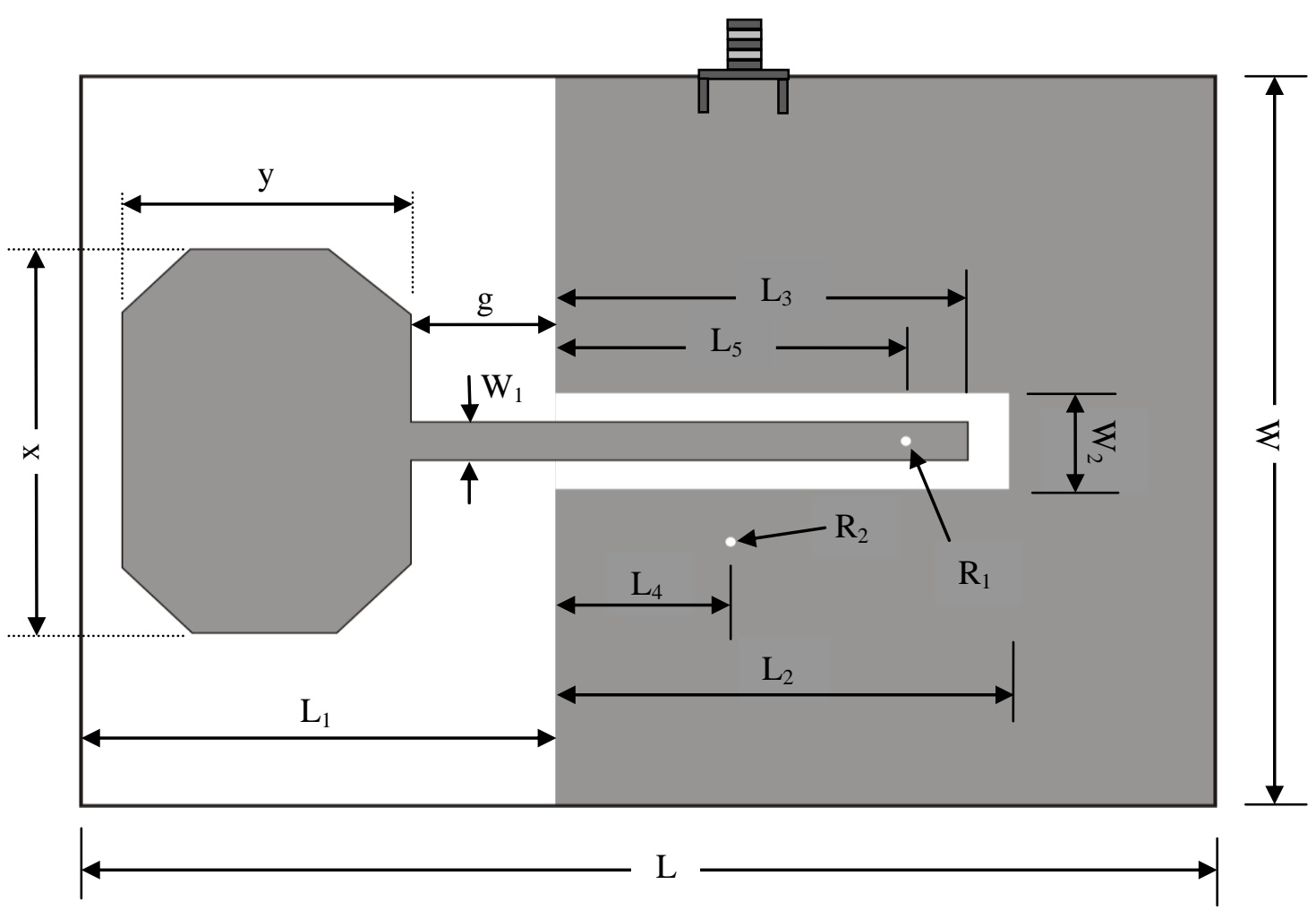

(a) Front side

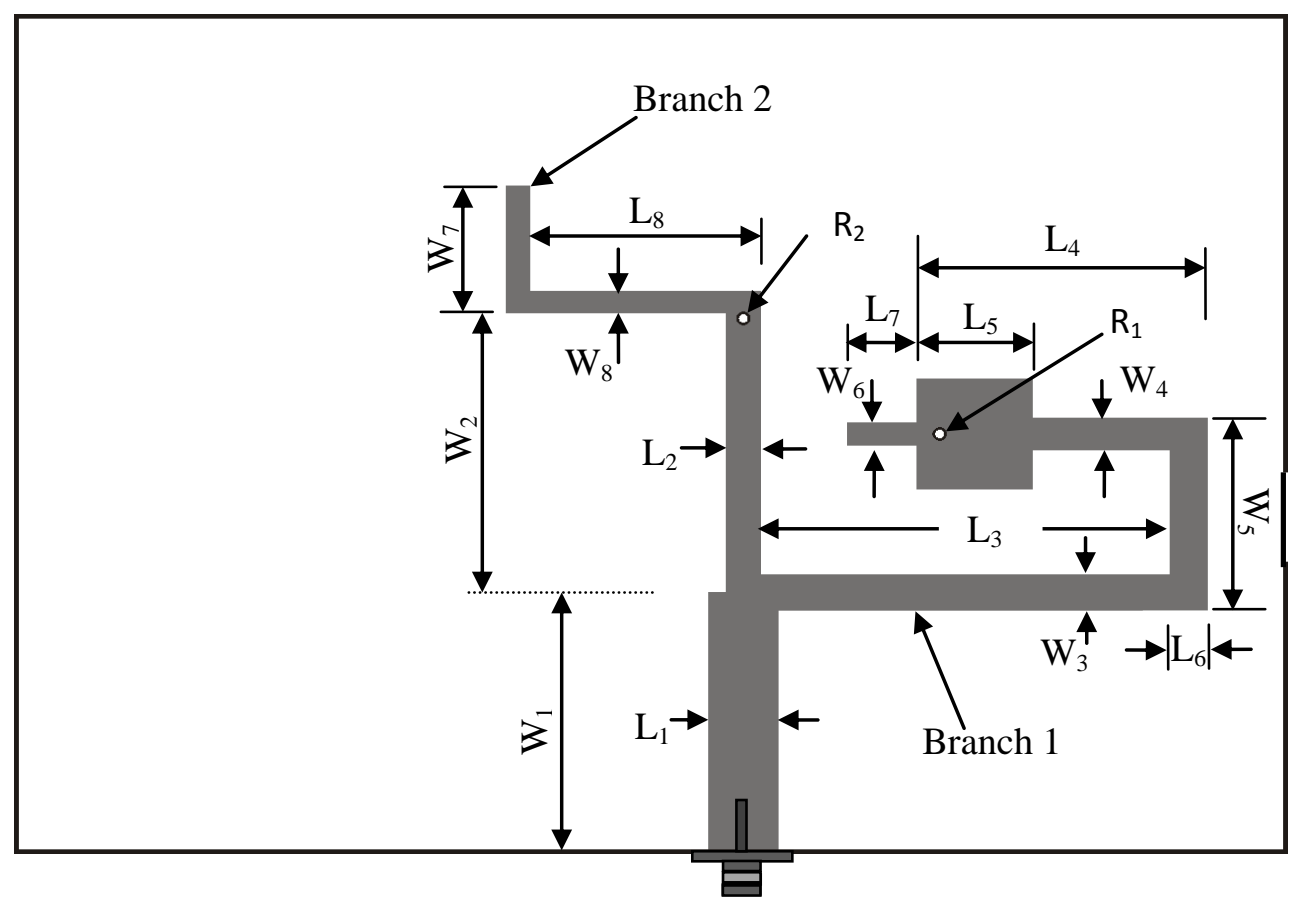

(b) Back side

Figure 1: Proposed antenna geometry

It consists of octagonal monopole and a slot on the ground plane. A branched microstrip feed structure is developed on the back side of the substrate. Two via-holes are embedded in the substrate to provide the feeding to the upper layer. One of the via-holes interconnects the monopole and branch 1 whereas the other one connects the ground and branch 2. As shown in Figure 1, branch 1 is used to excite the monopole which radiates a linear-polarized wave in $\mathrm{x}$-direction, and branch 2 is used to excite the slot which radiates a linearpolarized wave in y-direction. As an overall result of both, orthogonal linear-polarized waves are generated by the parallel connection of two radiation elements. By modifying the positions of two via-holes and widths of the two branches, equal amplitude of two modes can be achieved and $90^{\circ}$ phase 
difference can be achieved by changing the length of the each branch. Dual band operation with reasonable bandwidth can be achieved by adding stubs on the back side and by modifying the ground plane. Typical optimized dimensions of the proposed antenna geometry are listed in Table 1.

Table 1: Parameters of the optimized antenna geometry on front side

\begin{tabular}{|c|c|c|c|c|c|c|c|c|c|c|c|c|c|}
\hline Parameter & $\mathrm{L}$ & $\mathrm{W}$ & $\mathrm{L}_{1}$ & $\mathrm{~L}_{2}$ & $\mathrm{~L}_{3}$ & $\mathrm{~L}_{4}$ & $\mathrm{~L}_{5}$ & $\mathrm{x}$ & $\mathrm{y}$ & $\mathrm{g}$ & $\mathrm{W}_{1}$ & $\mathrm{~W}_{2}$ & $\mathrm{R}_{1}=\mathrm{R} 2$ (Via holes radius) \\
\hline Values(mm) & 55 & 38 & 23 & 22 & 20 & 8.5 & 17 & 20 & 14 & 7 & 2 & 5 & 0.25 \\
\hline
\end{tabular}

Table 2: Parameters of the optimized antenna geometry on back side feed

\begin{tabular}{|c|c|c|c|c|c|c|c|c|c|c|c|c|c|c|c|c|}
\hline Parameter & $\mathrm{L}_{1}$ & $\mathrm{~L}_{2}$ & $\mathrm{~L}_{3}$ & $\mathrm{~L}_{4}$ & $\mathrm{~L}_{5}$ & $\mathrm{~L}_{6}$ & $\mathrm{~L}_{7}$ & $\mathrm{~L}_{8}$ & $\mathrm{~W}_{1}$ & $\mathrm{~W}_{2}$ & $\mathrm{~W}_{3}$ & $\mathrm{~W}_{4}$ & $\mathrm{~W}_{5}$ & $\mathrm{~W}_{6}$ & $\mathrm{~W}_{7}$ & $\mathrm{~W}_{8}$ \\
\hline Values (mm) & 3 & 1.5 & 17.75 & 12.6 & 5 & 1.6 & 3 & 10 & 11.8 & 12.7 & 1.6 & 1.4 & 8.7 & 1 & 5.75 & 1 \\
\hline
\end{tabular}

The basic antenna with dimensions listed in Table $1 \&$ Table 2 was designed and simulated using HFSS v.13 and the obtained Return loss bandwidth vs. Frequency are depicted in Figure 2, axial ratio vs. frequency characteristics are depicted in Figure 3.

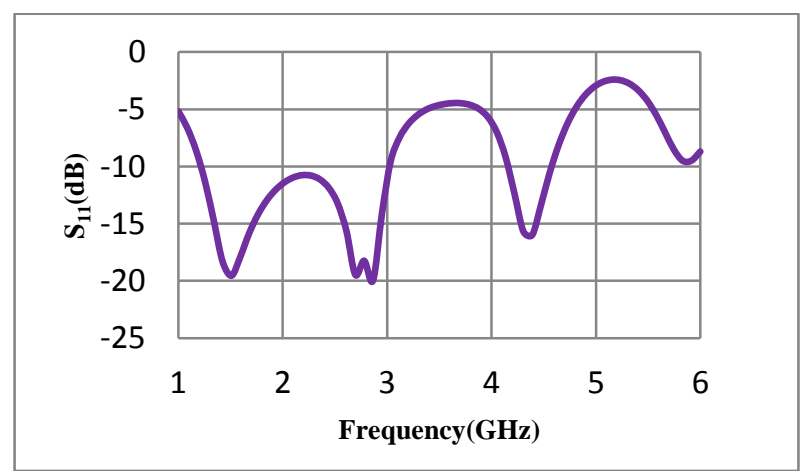

Figure 2: Return loss vs. frequency plot of antenna geometry of Figure 1

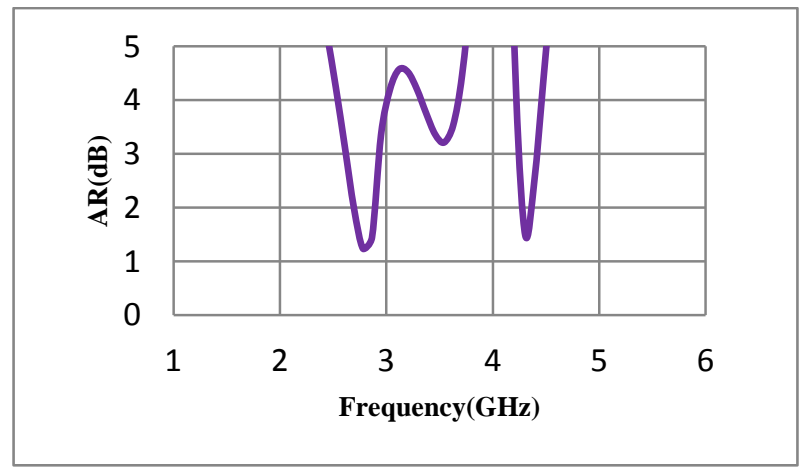

Figure 3: Axial ratio vs. frequency plot of antenna geometry of Figure 1

From Figures 2 and 3 it may be noted that the operating frequency ranges $(\mathrm{AR} \leq 3 \mathrm{~dB})$ are from 2.61 to $2.93 \mathrm{GHz}$ and 4.24 to $4.41 \mathrm{GHz}$ which also shows an overlapped impedance bandwidth at those frequencies.

The optimized results are carried out by simulating geometry in figure 1 using HFSS v.13 software and results are depicted in Figure 2 and Figure 3.

\section{PARAMETRIC STUDY FOR GEOMETRY OPTIMIZATION}

The proposed geometry in Figure 1 is simulated and optimized for better dual band operation. Some parameters are varied to get higher axial ratio bandwidth, some of them are slot length, slot width, slot gap, via-hole radius. Finally parameters are selected by considering trade-off between return loss bandwidth and axial ratio bandwidth.

\subsection{Effect of Change in Slot Length $\left(L_{2}\right)$}

The slot embedded in the ground gets excited by via-hole 2 interconnection with the ground which radiates linearly polarized wave in y-direction and slot length is optimized to 26mm (Solid line).

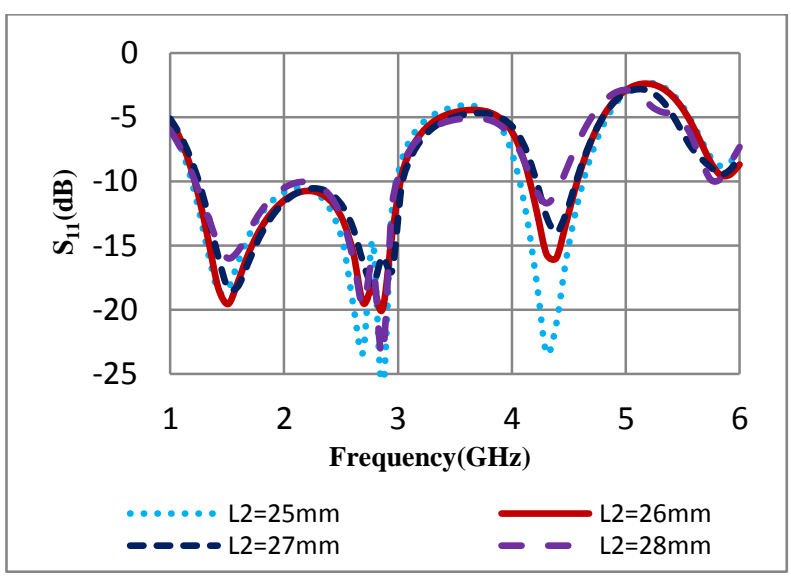

(a) Return loss vs. frequency plot for variation in slot length $\left(\mathbf{L}_{2}\right)$

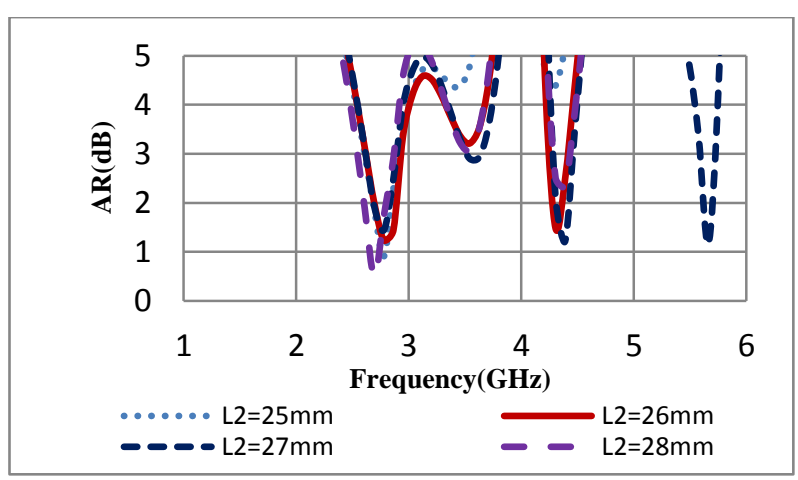

(b) Axial ratio vs. frequency plot for variation in slot length $\left(\mathbf{L}_{2}\right)$

Figure 4: Effect of change in slot length on return loss and axial ratio results 


\subsection{Effect of Change in Slot Width $\left(W_{2}\right)$}

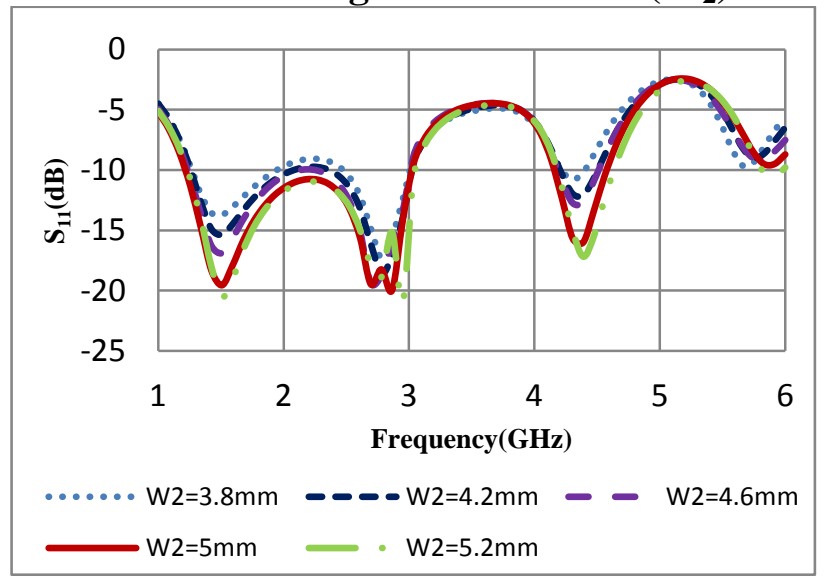

(a) Return loss vs. frequency plot for variation in slot width $\left(\mathbf{W}_{2}\right)$.

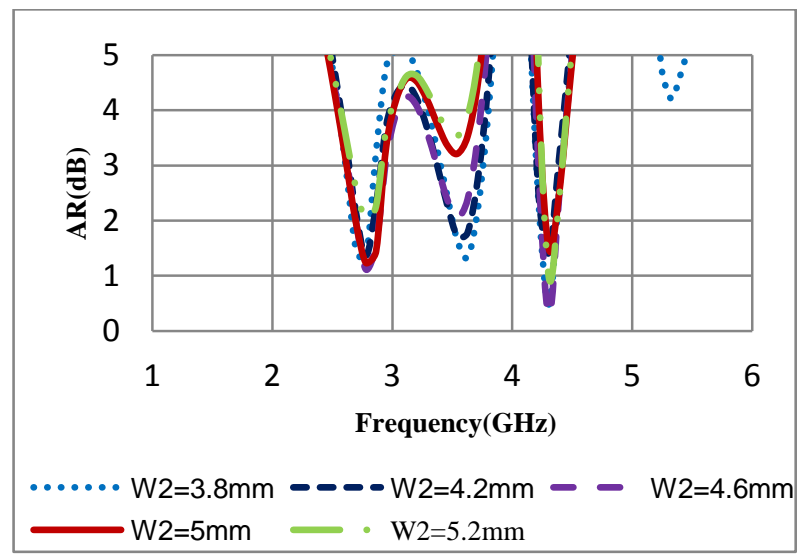

(b) Axial ratio vs. frequency plot for variation in slot width $\left(\mathbf{W}_{2}\right)$

Figure 5: Effect of change in slot width on return loss and axial ratio results

Slot width is main parameter in mutual coupling and providing good axial ratio bandwidth. This slot in a ground works as CPW transmission line which improves bandwidth. The Widths are changed but we got optimum results for $5 \mathrm{~mm}$ (Solid line).

\subsection{Effect of Change in Slot Gap (g)}

Slot gap is depicted by ' $\mathrm{g}$ ' in Figure 1 which is the gap between monopole and ground. Different shapes of monopole are studied and finally octagonal shape is selected for bandwidth improvement. After optimization gap is selected as $7 \mathrm{~mm}$ (Solid line).

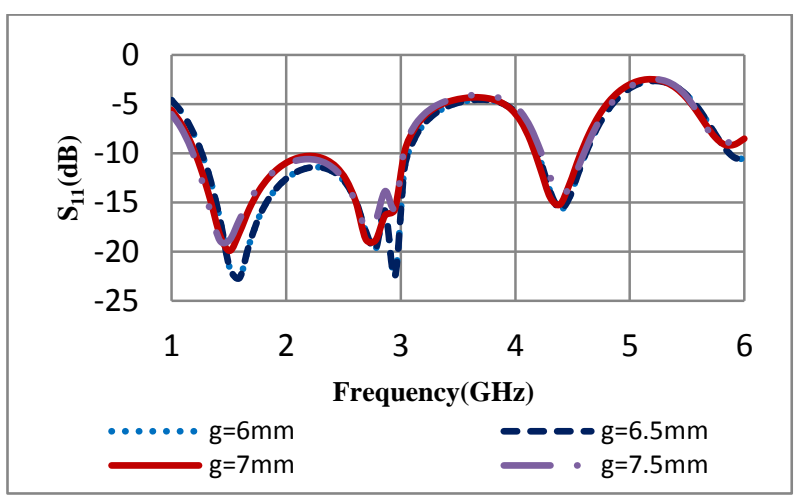

(a) Return loss vs. frequency plot for variation in slot gap (g).

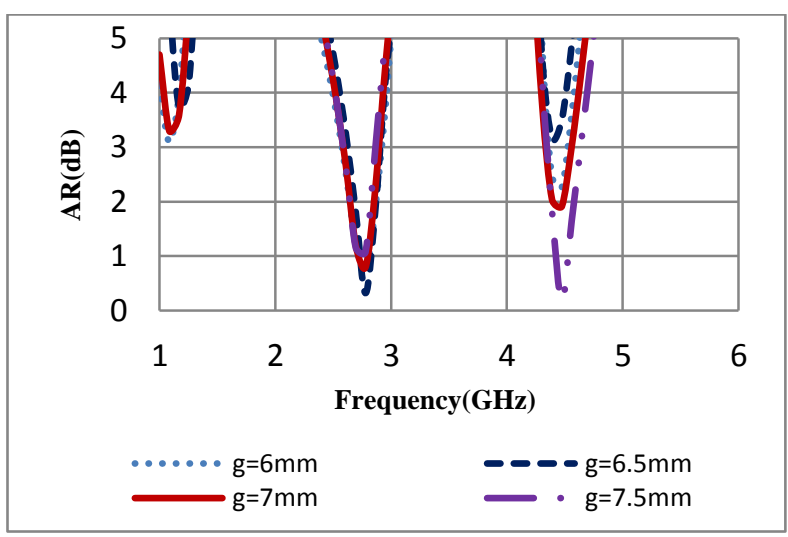

(b) Axial ratio vs. frequency plot for variation in slot gap (g)

Figure 6: Effect of change in slot gap on return loss and axial ratio results

\subsection{Effect of Change in Via Hole 1 Radius}

$\left(\mathbf{R}_{1}\right)$

It may be noted that via holes are used to bring feed to the upper side of substrate which is done by using two via holes, their dimensions are varied and optimized as $0.25 \mathrm{~mm}$ (Solid line) for both the via-holes. Branch 1 uses via-hole 1 to excite monopole on upper layer and branch 2 uses via-hole 2 to excite slot in the ground. 


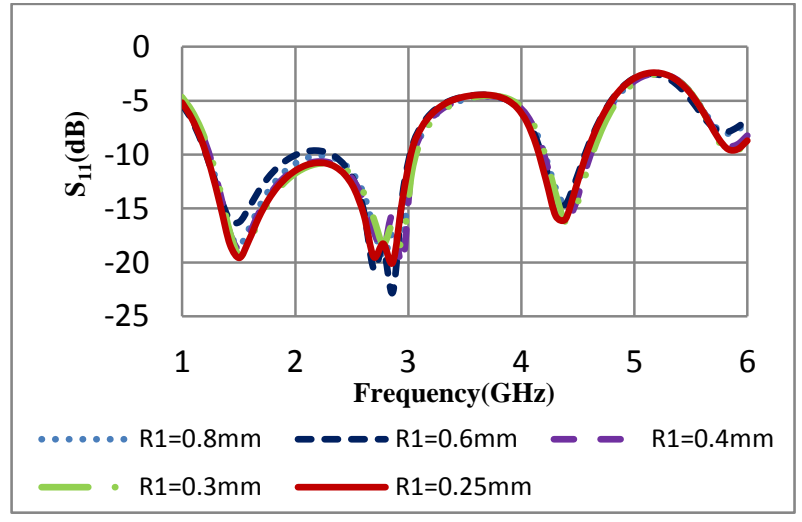

(a) Return loss vs. frequency plot for variation in radius of via-hole 1

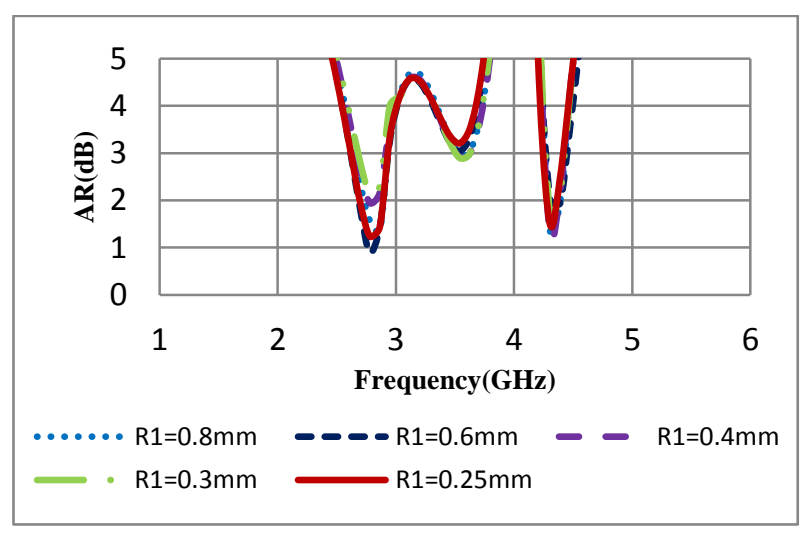

(b) Axial ratio vs. frequency plot for variation in radius of via-hole 1

Figure 7: Effect of change in radius of via-hole 1 on return loss and axial ratio results

\subsection{Effect of Change in Via Hole 2 Radius}

\section{$\left(\mathbf{R}_{2}\right)$}

The simulated results will not show much difference but we have standardized $0.25 \mathrm{~mm}$ size for both the via holes

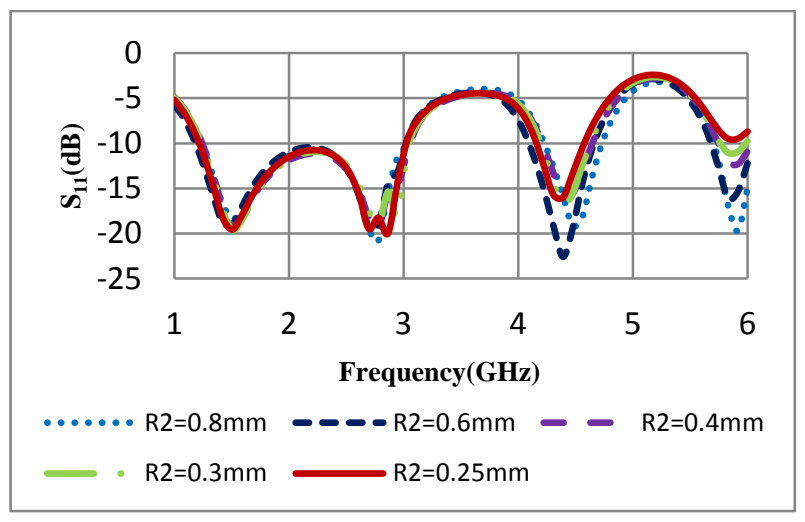

(a) Return loss vs. frequency plot for variation in radius of via-hole 2

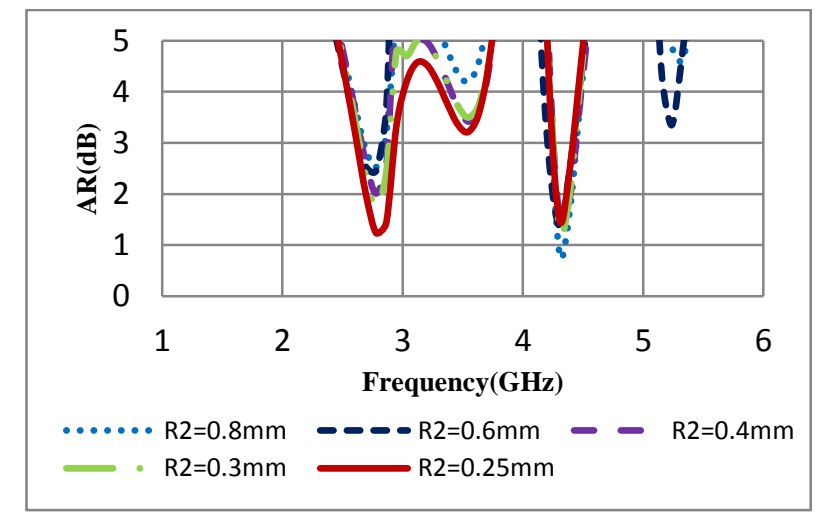

(b) Axial ratio vs. frequency plot for variation in radius of via-hole 2

Figure 8: Effect of change in radius of via-hole 2 on return loss and axial ratio results

\section{EXPERIMENTAL RESULTS OF \\ PROTOTYPE AND DISCUSSIONS}

The proposed geometry is fabricated as depicted in Figure 10. Experimental results of prototype are obtained using vector network analyzer and return loss is calculated. Simulated and measured results are compared and depicted in Figure 9 where we got good agreement between them. We can observe from the Figure 9 that there is good return loss bandwidth for both the working bands where we need circular polarization.

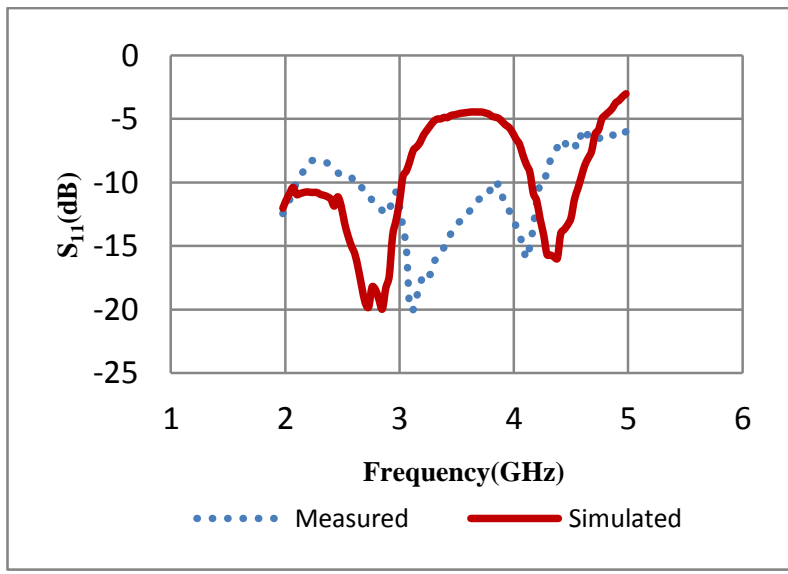

Figure 9: Measured and simulated $S_{11}$ results 

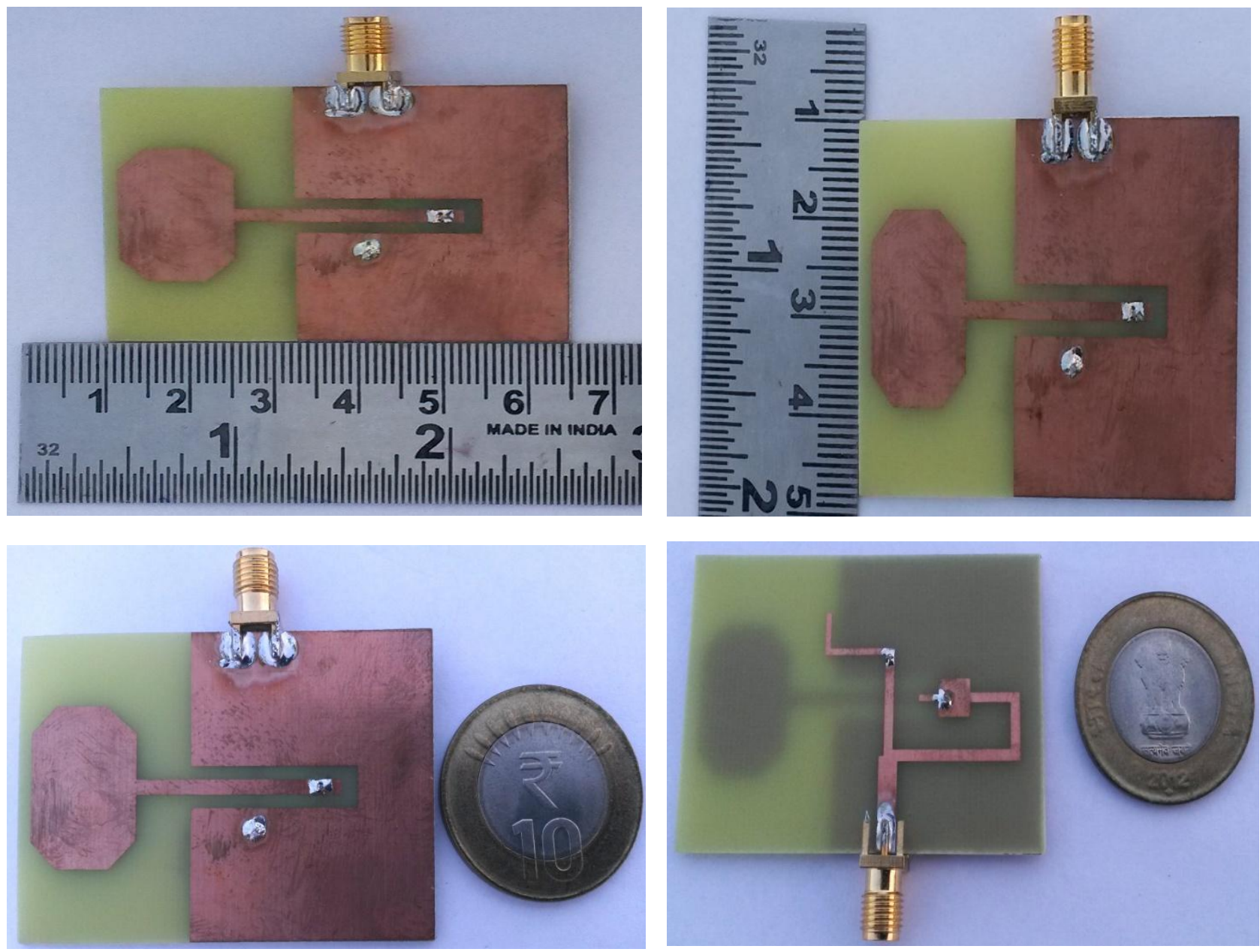

Figure 10: Fabricated geometry

\section{CONCLUSIONS}

A circularly polarized printed microstrip antenna for dual band presented and successfully simulated. This antenna can be made on standard FR4 substrate with $1.6 \mathrm{~mm}$ size. By exciting octagonal monopole and slot circular polarization is achieved. This design gives two bands for circular polarization as $2.61-2.93 \mathrm{GHz}$ and $4.24-4.41 \mathrm{GHz}$, having impedance bandwidths of $85.17 \%$ and $10 \%$ respectively and axial ratio bandwidths are $11.6 \%$ and $4 \%$ respectively. The antenna presented here is a good candidate for dual band antennas as overall bandwidth is better for circular polarization. Further by improving the monopole shape and slot we can introduce more bands by proper study of implementation of slot. So they can be used as multiband antennas for multipurpose applications. Furthermore, the antenna should be analytically modeled to understand its behavior with respect to axial ratio bandwidths for different geometrical changes.

\section{REFERENCES}

[1] Foudazi, A., H. R. Hassani, and A. Frotanpour. "A novel broadband circularly polarized printed monopole antenna." Antennas and Propagation Conference (LAPC), 2011 Loughborough. IEEE, 2011.

[2] Wang, Mao-Ze, et al. "Design of CPW-fed circularly polarized antenna with two orthogonal slots." Progress in Electromagnetics Research Letters, vol. 33, pp. 109-117, 2012.
[3] Christina F. Jou, Jin-Wei Wu, and Chien-Jen Wang, "Novel broadband monopole antennas with dual-band circular polarization," IEEE Trans. on Antennas and Prop., vol. 57, no. 4, pp. 1027-1034, April 2009.

[4] Chiou, J.-Y., J.-Y. Sze, and K.-L. Wong, "A broad-band CPW-fed strip-loaded square slot antenna," IEEE Trans. Antennas Propag., vol. 51, no. 4, pp. 719-721, 2003.

[5] Joseph, R. and T. Fukusako, "Bandwidth enhancement of circularly polarized square slot antenna," Progress In Electromagnetics Research B, vol. 29, pp. 233-250, 2011.

[6] Sze, J.-Y., K.-L. Wong, and C.-C. Huang, "Coplanar waveguide-fed square slot antenna for broadband circularly polarized radiation," IEEE Trans. Antennas Propag., vol. 51, no. 8, pp. 2141-2144, 2003.

[7] Chou, C. C., K. H. Lin, and H. L. Su, "Broadband circularly polarized cross-patch-loaded square slot antenna," Electron. Lett., vol. 43, no. 9, pp. 485-486, 2007.

[8] Chen, Y. B., X. F. Liu, Y. C. Jiao, and F. S. Zhang, "CPW-fed broadband circularly polarized square slot antenna," Electron. Lett., vol. 42, no. 19, pp. 1074-1076, 2006.

[9] Sze, J.-Y. and C.-C. Chang, "Circularly polarized square slot antenna with a pair of inverted-L grounded strips," 
IEEE Antennas Wirel. Propag. Lett., vol. 7, pp. 149-151, 2008.

[10] Y. M. Cai, K. Li, Y. Z. Yin and W. Hu, "Broadband Circularly Polarized Printed Antenna With Branched Microstrip Feed," in IEEE Antennas and Wireless Propagation Letters, vol. 13, pp. 674-677, 2014.

[11] Bao, X. L. and M. J. Ammann, "Dual-frequency circularly polarized patch antenna with compact size and small frequency ratio," IEEE Trans. Antennas Propag., vol. 55, no. 7, pp. 2104-2107, 2007.

[12] Nayeri, P., K.-F. Lee, A. Z. Elsherbeni, and F. Yang, "Dual-band circularly polarized antennas using stacked patches with asymmetric U-slots," IEEE Antennas Wirel. Propag. Lett., vol. 10, pp. 492-495, 2011.

[13] Chen, C. H. and E. K. N. Yung, "Dual-band circularlypolarized CPW-fed slot antenna with a small frequency ratio and wide bandwidths," IEEE Trans. Antennas Propag., vol. 59, no. 4, pp. 1379-1384, 2011.

[14] Liao, W. and Q.-X. Chu, "CPW-fed square slot antenna with lightening-shaped feedline for broadband circularly polarized radiation," Progress In Electromagnetics Research Letters, vol. 18, pp. 61-69, 2010.

[15] Chang, K.-M., “A novel design of a CPW-fed square slot antenna with broadband circular polarization," Microwave Opt. Technol. Lett., vol. 48, pp. 2456-2459, Sept. 2006.

[16] Sze, J. Y., K. L. Wong, and C. C. Huang, "Coplanar waveguide-fed square-slot antenna for broadband circularly polarized radiation," IEEE Trans. Antennas Propag., vol. 51, pp. 2141-2144, Aug. 2003.

[17] Nasimuddin, Z. N. Chen, and X. Qing, "Symmetricaperture antenna for broadband circular polarization," IEEE Trans. Antennas Propag., vol. 59, pp. 3932-3936, Oct. 2011.

[18] Seyyedrezaei, S.F., H.R. Hassani, S.M.A. Nezhad. A novel small size CPW-fed circular polarized antenna. In Loughborough Antennas and Propagation Conference (LAPC), November 2011.

[19] Pourahmadazar, J., C. Ghobadi, J. Nourinia, N. Felegari and H. Shirzad. Broadband CPW-fed circularly polarized square slot antenna with inverted-L strips for UWB applications, Antennas and Wireless Propagation Letters, IEEE, vol. 10, pp. 369-372, 2011.

[20] Sze, J.-Y., C.I.G. Hsu, Z.-W. Chen and C.-C. Chang. Broadband CPW-fed circularly polarized square slot antenna with lightening-shaped feedline and inverted-L grounded strips, IEEE Transactions on Antennas and Propagation, vol. 58, no. 3, pp. 973-977, 2010. 